\title{
f Particularidades de un modelo económico de un espacio fronterizo nordpatagónico. Neuquén, Siglos XVIII y XIX'
}

Gladys Varela - Carla Manara ${ }^{2}$

El objetivo del presente trabajo consiste en analizar las particulares características y condiciones de un modelo económico, que con algunas variantes, se mantuvo en la región nordpatagónica desde la etapa colonial tardía hasta la campaña militar de 1879. Dicha permanencia fue producto de una continua readaptación de las relaciones fronterizas en el marco del orden dominante. Este proceso no sólo afectó a los indígenas sino que comprometió a todas las partes intervinientes. Cabe precisar que la desestructuración del modelo planteado, entendida como la ruptura definitiva de los patrones que lo habían caracterizado, se dio recién a partir del avance militar de 1879. En efecto, hasta entonces los factores que podrían pensarse como desestructuradores, habrían actuado como verdaderos desafíos para una nueva reestructuración.

En el siglo XVIII, las tribus neuquinas, favorecidas por su ubicación geográfica, realizaban un activo comercio con los centros coloniales chilenos y cuyanos. También lo hacían con otros grupos indígenas de uno y otro lado de

1-Este trabajo forma parte del proyecto de investigación: Sociedad indigena y relaciones fronterizas. Neuquén, 1750-1890. Dirigido por la Lic. Gladys Varela.

2-Fac. de Humanidades, Univ. Nac. del Comahue (UNCo) 
la cordillera. Se generó un verdadero comercio fronterizo en el que huilliches y pehuenches actuaron como intermediarios entre el mercado chileno, consumidor de ganados, y la pampa húmeda, productora de los mismos. El circuito ganadero consolidado en esta etapa estaba íntimamente relacionado con la exportación de carnes saladas, cueros y sebos que realizaban los hacendados chilenos.

A partir de 1810, las guerras de independencia de Argentina y Chile, provocaron algunos cambios. Aunque Chile había ya constituido su primer gobierno patrio, los realistas -a partir de 1813-comenzaron a fortalecerse con el apoyo de divisiones enviadas desde Lima, concentrando sus fuerzas en Concepción, Talcahuano, Los Angeles y Chillán, infiriendo varias derrotas a los patriotas. Al año siguiente, el avance de las fuerzas monárquicas sobre los campos de Rancagua produjeron la caída del gobierno patrio. Sin embargo, la reconquista del poder por parte de los realistas fue efímera, ya que en 1817 fueron derrotados en Chacabuco y posteriormente en Maipú.

Mientras los patriotas se jactaban de la destrucción de los focos rebeldes, en forma inesperada los restos de estas fuerzas se reorganizaron rápidamente al sur del Bío Bío. Así comenzó, un complejo proceso que se conoce como "guerra a muerte". Este enfrentamiento entre patriotas y realistas se centró durante los primeros años en el sur de Chile y posteriormente, liderado por los hermanos Pincheira, se trasladó a los ricos valles del N.O neuquino.

La adhesión de los grupos mapuches y pehuenches a las guerrillas realistas, favoreció la organización de malones como verdaderas empresas económicas, complejizando los circuitos mercantiles de la etapa anterior. Estas fuerzas organizadas en defensa de la causa del rey, asolaron simultáneamente los poblados, haciendas y ciudades a ambos lados de la cordillera hasta entrada la década del $30^{3}$.

Finalizado el accionar de las guerrillas pincheirinas, surgieron nuevas situaciones de tensión en el espacio fronterizo estudiado. En esta oportunidad los

3-Las autoridades chilenas consideraron que a partir de 1825 se habian librado del accionar de las guerrillas. Esto se sustentaba, por un lado, en que se había concretado el parlamento de Tapihue firmando la paz con los araucanos.Por otro lado,las fuerzas pincheirinas se habian trasladado a tierras argentinas. Sin embargo la documentación da cuenta de que las ciudades continuaban siendo asoladas por estos grupos evidenciando una gran capacidad de movilización. Por ejemplo, en 1829 la Comandancia Principal de la Pcia. de Colchagua informó que unos 70 hombres de Pincheira atacaron las haciendas de Talcaregua. Un año después los grupos guerrilleros invadieron el centro-sur de Chile bajando por varios puntos de la cordillera. (Documentación citada en CONTADOR VALENZUELA, A.M, (1989): cap VII, parte VIII.) $\mathrm{Al}$ respecto cabe mencionar también los asaltos dirigidos por Miguel Senosiaín, General realista, refugiado entre los pincheirinos, que entre 1825 y 1827 asoló poblados chilenos como Parral. Cfr. (KEUN, Ricardo, 1986:296-298) [Así nació la frontera... Santiago de Chile, Ed. Antártica] 
cabecillas fueron individuos que, vinculados al proceso anteriormente mencionado, emergieron como promotores de conflictos, generando permanentemente intrigas políticas entre los gobiernos republicanos, movilizando para sus fines a los indígenas de ambos lados de la cordillera.

Para la segunda mitad del siglo XIX, dentro del seno de las sociedades indígenas de la nordpatagonia, se estaban conformando paulatinamente grandes unidades políticas, lideradas por poderosos caciques que, con gran autonomía, fueron capaces de combinar el comercio, la guerra y la diplomacia a través de la firma de diversos tratados con los gobiernos argentinos y chilenos.

Finalmente, el corrimiento de la frontera y el intento de someter a las tribus en aras de la unificación política y territorial por parte de ambas repúblicas, desestructuró definitivamente al mundo indígena y quebró el modelo económico que había perdurado dos siglos.

\section{Neuquén, un espacio muy particular}

Neuquén desde la etapa prehispánica, fue siempre un área de convergencia de diversas corrientes poblacionales que, provenientes de Cuyo, Patagonia septentrional, Chile o de la región pampeana, aportaron diferentes patrones culturales. Desde épocas muy tempranas, la comunicación entre los grupos indígenas fue intensa, especialmente con los del sector oeste de la cordillera ${ }^{4}$. En este contexto los Andes nunca fueron una barrera infranqueable ya que sus pasos relativamente bajos facilitaron una fluída circulación de personas, bienes y elementos culturales.

Asimismo la diversidad de recursos, la variedad ambiental y los refugios naturales fueron desde siempre factores de estímulo y atracción para afincarse en tierras neuquinas. Desde el siglo XVII se observa una estrecha relación entre las sociedades de Araucanía, nordpatagonia y las pampas. Estudiar la articulación de estas regiones como partes integrantes de un todo, es un requisito indispensable para entender la verdadera dinámica de los grupos interactuantes y la complejidad de las relaciones fronterizas.

El análisis de este espacio fronterizo integrado económica y socialmente,

4-Existen algunas evidencias de que en el siglo XVII, los indigenas cordilleranos obtenían vacas y sobre todo caballos salvajes procedentes de las pampas para aprovisionar a los araucanos de Chile. (MANDRINI, Raúl 1984).

5-Ya en la etapa preincaica, indigenas de Neuquén proveian de sal a los grupos de Chile, obtenida en las minas de Truquico, localizadas al noroeste de la provincia. (VARELA, Gladys y BISSET, Ana María 1993) 
tiene sus antecedentes en el modelo propuesto por Carlos Sempat Assadourian (1982) para el siglo XVII . En éste, la nueva organización del espacio del área andina giraba en torno a dos polos dinámicos o de crecimiento: Lima y Potosí. La "influencia directa del mercado minero", a través de la demanda, tanto de medios de producción como de medios de subsistencia, contribuyó entonces a la mercantilización de ese espacio y determinó la especialización regional dentro de él. Sin embargo, y respondiendo al objetivo del presente trabajo, encontramos que este modelo siguió vigente durante los siglos XVIII y XIX, en los cuales ya no eran Lima y Potosí los polos dinamizadores ${ }^{7}$, sino otras regiones que habían comenzado a generar importantes demandas, supliendo el papel articulador de aquellos centros ${ }^{8}$. (Tandeter,E. 1992:19-22)

Así Neuquén se articuló claramente a partir del siglo XVIII a este sistema como región de abastecimiento, especialmente de los centros de Chillán y Antuco que se conectaban con el puerto de Talcahuano. También existía comunicación directa con Valdivia desde el sur de la actual provincia ${ }^{9}$. A su vez los

6-En este modelo ambos polos crean flujos o efectos de arrastre sobre otros conjuntos del espacio geográfico y económico. Estas zonas polarizadas provocan una segunda ola sobre otras regiones nuevas y más alejadas de los centros (áreas periféricas), generando una red de intercambio internos. En este esquema, Chile estaba inserto en el espacio peruano, en calidad de periferia. Como tal, abastecía a Potosí y a Lima de ganado en pie y derivados. El pais trasandino, comenzó entonces a generar su propia demanda estimulando a las regiones cuyanas y neuquina.

7-La fuerte crisis del siglo XVII alteró la producción minera de Potosi e influyó sobre todas las áreas que dependian de ese importante mercado. Hubo una baja generalizada en las demandas pero la crisis no fue definitiva. Hacia la primera mitad del siglo XVIII, la producción minera tuvo una relativa recuperación, muy notoria ya para la década de 1730 y, entre 1740 y 1780 , hubo un crecimiento constante para comenzar a declinar otra vez. Paralelamente al alza de la producción minera potosina, el Alto Perú registró un crecimiento de población y una expansión de la producción agrícola. Pese a los vaivenes económicos, todavía es posible pensar en Potosí como un rentable mercado para las economías regionales durante el siglo XVIII, sin que esto signifique la recuperacón de su papel articulador que le cupo a fines del siglo XVI y comienzos del XVII. ( TANDETER, E. 1992).

8-La región surandina ( La Paz, Charcas, Arica, Arequipa, Cusco y Cochabamba), a fines del siglo XVIII era la zona más mercantilizada de los virreinatos del Perú y del Río de la Plata. Estas zonas productoras cuyo desarrollo agrario y manufacturero había respondido directamente a las demandas de Potosí, no se retrotrajeron uniformemente ante la caida del centro minero. La exportación de cueros ya era un producto privilegiado en las exportaciones chilenas desde el siglo XVIII. Antes de que terminase el periodo colonial, las exportaciones ascendían a más de un millón de cueros anuales y hacia Europa, Estados Unidos y el Caribe. Otro alternativa mercantil, era la colocación de caballos en el Bajo Perú, aunque las cantidades eran muy reducidas en comparación con el siglo XVIII. El siglo XIX se caracterizó por una apertura de puertos y mercados a lo largo de las costas del Pacífico. Los animales en pie, cueros y sebo seguian siendo mercancías muy demandadas, por consiguiente, tuvieron una rápida inserción en nuevos mercados. La vigencia de las exportaciones chilenas garantizaba la articulación del noroeste neuquino.

9- Tal como observaron Villarino en el siglo XVIII y Cox en el siglo XIX. 
indígenas neuquinos actuaron como nexo con la pampa húmeda, productora por excelencia de ganados. Ese rol de intermediario estuvo vigente durante todo el siglo XVIII y gran parte del XIX. La influencia que ejercía Chile sobre Neuquén era tan directa y las prácticas mercantiles estaban tan arraigadas, que ni la creación del Virreinato del Río de la Plata, ni la independencia de Argentina pudieron desbaratarlas. Los límites geográficos y las jurisdicciones políticas impuestas no tuvieron efecto. La marginalidad en relación a los centros de poder confirió un aislamiento muy conveniente para el funcionamiento del modelo. Sin embargo, los grupos indígenas no fueron indiferentes a las transformaciones y conflictos planteados en el seno de las políticas dominantes.

\section{Etapa colonial tardía}

Para fines del siglo XVIII, Neuquén estaba ocupado por dos "naciones"10: al norte la pehuenche y la huilliche al sur. Para esta época las tribus neuquinas, favorecidas por su ubicación geográfica, realizaban un activo comercio con los centros coloniales chilenos y cuyanos y también con los grupos indígenas transcordilleranos, pampeanos y nordpatagónicos.

Los caciques de estas tierras tenían un control absoluto de los pasos cordilleranos, de las rutas de arreo y de los valles fértiles y abrigados, que sirvían como campo de engorde para el ganado que, proveniente de la llanura pampeana se colocaba en Chile. Se generó un activo comercio fronterizo en el que huilliches y pehuenches actuaron necesariamente como intermediarios.

El volumen e importancia del trueque adquirió dimensiones notables", tanto que las autoridades coloniales chilenas celebraron parlamentos para fijar las fechas y los lugares donde se realizarían las ferias de intercambio. El circuito ganadero, iniciado y consolidado en la etapa colonial, estaba intimamente relacionado con la demanda de los indígenas de la Araucanía y con la actividad exportadora de carnes saladas, cueros y sebos que realizaban los hacendados y comerciantes trasandinos.

La abundancia de ganado en las pampas, permitió a las tribus neuquinas proveerse fácilmente de este recurso, a veces a través de incursiones a aquellos

10- En los documentos de la época es común el uso de esta categoría, utilizando el término "nación" como equivalente al de "tribu".

11-Entre los cronistas del siglo XVIII que confirman estos datos podemos mencionar a VILLARINO, Basilio: "Diario del piloto de la Real Armada, Don..., del reconocimiento que hizo en el río Negro, en la costa oriental de la Patagonia, el año de 1782". (De Angelis, P. 1969). 
territorios, otras, mediante el trueque con tribus pampeanas que acercaban los rebaños hasta el río Colorado'2.

Con el tiempo, algunos caciques comenzaron a adquirir cierto poder, prestigio y riqueza. La circulación de bienes por sus territorios, debía implicar el pago de peajes, a veces voluntario, y en otros casos limitado al robo $y$ apropiación de las mercancías transportadas. Por otra parte el ganado antes de ser vendido en Chile, debía ser engordado en los valles neuquinos luego de sufrir largas travesías. Es probable que el arrendamiento de pasturas haya sido otra forma de adquisición de bienes para las tribus locales. (Varela y Bisset 1992)

Para analizar la economía de estos grupos y conocer el funcionamiento del modelo económico, sin duda debemos puntualizar dos aspectos esenciales. El primero tiene que ver con la movilidad de los grupos y el segundo con la estrecha relación y dependencia con los núcleos fronterizos de poblaciones sedentarias.

\section{Control y manejo del espacio}

El patrón de movilidad espacial, determinado por las estaciones y en función de la obtención de recursos fue, naturalmente, previo a la adopción del ganado. La incorporación de los animales traídos por los europeos, marcó un cambio significativo y la adecuación de ese patrón a las necesidades derivadas de la cría y cuidado del ganado, ya no sólo para la propia manutención sino para la comercialización.

Esa adecuación se percibe claramente en la implementación de un sistema transhumante de veranada e invernada. Entendemos a la transhumancia como la conducta resultante de una adaptación ambiental enfocada a asegurar buenas condiciones para los rebaños. Se trata de un sistema productivo que incluye la "apropiación" y "explotación" de animales y pasturas (Baied 1985). De allí que sus campamentos de veranada e invernada se localizaran en territorios constituidos por ambientes naturales complementarios.

En una sociedad de ganaderos y comerciantes, el modelo económico, vinculado íntimamente al manejo territorial, adquirió determinados patrones de asentamiento. Las tolderías se diseminaban a lo largo de los valles de los cursos fluviales más importantes. Es probable que cada unidad familiar dispusiera

12-Véase CRUZ, Luis de 1a: "Viaje desde el puerto de Ballenar hasta la ciudad de Buenos Aires". (De Angelis 1969:T.VII). 
de amplios territorios, permitiendo la rotación de pasturas sin necesidad de grandes desplazamientos, posibilitando una permanencia relativamente estable en dos o tres campamentos a lo largo del año (veranada e invernada). Contribuyó a esto la condición ecuestre, que les permitió controlar rodeos que pastaban en valles más o menos alejados de sus tolderías (Varela y Bisset 1992).

En cuanto a la distribución de sus asentamientos, en ningún caso se observa una concentración importante de población. En cambio las fuentes confirman que las tolderías mantenían cierta distancia unas de otras aunque estaban vinculadas entre sí, y si bien no conformaban poblados o aldeas, constituían núcleos perfectamente integrados. Los puntos de instalación se repetían a lo largo del tiempo con pequeñas variaciones.

Era también fundamental la cercanía a las vías de traslado de ganado y a los pasos cordilleranos sobre los que se ejercía un estricto control. Estas rutas estaban vigiladas desde divisaderos, pequeños recintos pircados, ubicados en las cimas de los cerros, donde se encendían hogueras, para dar aviso sobre la llegada del ganado o de malones organizados por tribus enemigas ${ }^{13}$.

\section{Relaciones interétnicas en la frontera}

En cuanto a las vinculaciones fronterizas con sociedades sedentarias, en nuestro caso con los enclaves chilenos y mendocinos, percibimos para fines del siglo XVIII una relación bastante simétrica. Los indígenas responden a demandas coloniales, especialmente de ganado, y reciben a cambio cereales y productos manufacturados de índole sumamente variada y en cantidades considerables (Varela y Bisset 1992).

En las transacciones allende los Andes, los indígenas neuquinos no sólo llevaban animales sino también sal y tejidos, elementos tremendamente apreciados en aquellos tiempos. La primera por su escasez en Chile y los segundos por la excelente calidad de los ponchos indígenas que se impusieron como prenda habitual entre los habitantes del campo chileno. Mantas, ponchos y chamales, también eran ubicados entre las tribus pampeanas, canjeándolos por haciendas que luego comercializarían en Chile.

También trataban con conchavadores chilenos que ingresaban a tierras indias con caravanas repletas de productos para intercambiar en las tolderías. Una vez entregadas las mercancías demandadas, preferentemente armas,

13-Estos puestos de altura fueron detectados en los valles neuquinos de El Malleo y Quilaca por GONI, R.(1986).

- Instituto de Historia Regional - Facultad de Ciencias Humanas - Universidad Nacional de La Pampa - 
bebidas, chaquiras, tijeras, cuchillos, estribos, entre otras tantas, regresaban arreando el ganado obtenido a modo de pago.

Si bien durante el siglo XVIII la sociedad indígena y la hispano-criolla mantuvieron estrechas relaciones comerciales, los nativos no permitieron la instalación de fortines ni autorizaron la presencia permanente de funcionarios, sacerdotes o hacendados dentro del territorio que hoy ocupa la provincia de Neuquén. El ingreso a estas tierras estaba estrictamente controlado y sólo a través de salvoconductos o acuerdos previos, algunos viajeros y misioneros pudieron transitar los dominios de los caciques principales.

Para la realización de un viaje por tierras neuquinas o durante la celebración de un parlamento se solía entregar abundantes regalos a los indígenas. En el primer caso para obtener su consentimiento y en el segundo, para lograr su asistencia y participación. Recordemos la pormenorizada descripción que hiciera Don Luis de la Cruz acerca de los regalos que debió entregar a lo largo de su recorrido por tierras pehuenches y ranqueles (CRUZ, Luis de la, 1969), estrategia imprescindible para asegurar su tránsito.

La entrega en los parlamentos de obsequios preferenciales y títulos especiales (por ejemplo el de Cacique-Gobernador) a determinados caciques, fue reforzando paulatinamente la autoridad de algunos jefes, hasta convertirlos en interlocutores válidos de su grupo. Con estos mecanismos de jerarquización, las autoridades coloniales pretendieron superar las dificultades iniciales que significaba dialogar con todos los loncos de igual rango presentes en la reunión (Méndez Beltrán, 1982).

\section{Comienzos de la etapa republicana}

A partir de 1810, la sociedad fronteriza de los Andes meridionales se vio involucrada en los vaivenes de las guerras de independencia. Si bien nuestro objetivo principal se centra en la permanencia del modelo económico descripto, es indudable que los acontecimientos revolucionarios provocaron importantes cambios políticos, pero los circuitos mercantiles iniciados en la etapa anterior se mantuvieron vigentes.

La transición entre el viejo orden colonial y el nuevo esquema independentista significó un proceso mucho más complejo de lo que tradicionalmente se ha querido reconocer. La batalla de Maipú de 1818, en la cual los realistas fueron derrotados por los patriotas chilenos, no fue definitiva como pensó el gobierno republicano ya que al poco tiempo comenzaron a surgir fuerzas de 
resistencia que atacaban simultáneamente distintos puntos fronterizos.

Los realistas dispersos y marginados del sistema imperante, persistieron en su lucha por reinstaurar el poder del rey, desatando una prolongada y constante oposición política que dio lugar a la conocida "guerra a muerte". Si bien esta guerra se concentró inicialmente al sur del Bio Bio, rápidamente se trasladó al este de la cordillera, en territorio argentino, involucrando a las actuales provincias de Neuquén y sur de Mendoza como centros de operaciones. Desde allí se organizaban asaltos y malones a poblados y haciendas a ambos lados de los Andes.

\section{Algunas cuestiones en debate}

El análisis de los primeros años de la etapa republicana ha derivado en controvertidas interpretaciones. La rivalidad entre independentistas y realistas, sobre todo en la frontera sur de Chile, ofrece aún varias aristas confusas. La historiografía tradicional ha legitimado la idea de un apoyo incondicional de toda la sociedad a la causa de la emancipación y, en un intento de desacreditar al enemigo, minimizó la importancia de la resistencia armada del sur chileno.

La elite dirigente consideró, al menos formalmente, que se trataba de grupos marginales y aislados que, integrados por "bandoleros", "asesinos" y "delincuentes", se habían asociado a los últimos restos del ejército español.

El conflicto se agudizó cuando los jefes realistas hicieron alianzas con las tribus de la Araucanía y se ampararon en sus tierras. La adhesión de varios grupos indígenas a la causa monárquica aumentó la peligrosidad de los grupos enemigos de la patria. Los jefes del ejército real lograron reorganizar sus fuerzas tomando como principal centro de operaciones la ciudad de Concepción, dominio que no se prolongó por mucho tiempo ya que los realistas, vencidos por el General Freire, se replegaron hacia el sur. No hay dudas, como lo observaron varios viajeros de aquellos años, que el sur chileno seguía siendo efectivamente realista (Poeppig 1960).

Fueron los historiadores e intelectuales liberales los que desataron la bipolaridad entre civilización y barbarie. Se construyó la imagen de una Santiago culta y civilizada frente al sur, cuna de indios y mestizos, bárbara y salvaje (Bengoa 1992: cap.2). El sueño inicial de los criollos patriotas de buscar sus raíces y el nacimiento de su nacionalidad en la integración con los valientes araucanos, que con su sangre habían resistido los embates del conquistador, se 
disipó rápidamente.

La alianza indígena con los jefes del ejército español, provocó la reacción de una historiografía antiindigenista que negativizó la imágen del indio y sentó las bases de una justificación ideológica para la posterior "pacificación" de la Araucanía. Surge así, la necesidad de revisar el discurso antipatriota, para resignificar la visión oficial de los acontecimientos acaecidos en la frontera surandina.

Pretendemos también tomar distancia de aquellos historiadores que han parcializado el análisis etnohistórico al desvincular la historia de los grupos de la Araucanía de los instalados al este de la cordillera. Hoy día sabemos que es imposible comprender el desarrollo de los distintos grupos étnicos asentados a ambos lados de los Andes, sino lo hacemos asociándolos a un mismo devenir histórico y en un espacio económicamente integrado que se iniciaba en las pampas, pasaba por el norte patagónico y culminaba allende del cordón andino.

\section{Connotaciones de la guerra a muerte}

El enfrentamiento entre los partidarios del rey y los patriotas adquirió connotaciones muy particulares y desató la llamada "guerra a muerte". Esta se extendió durante casi dos décadas y estableció una serie de contactos fronterizos muy particulares ${ }^{14}$. La violencia fue el denominador común entre los dos bandos y una constante amenaza para los poblados de ambos lados de la cordillera. En tales condiciones, la frontera sur, surgió como un lugar propicio para el accionar bélico.

Debilitado el frente realista por la desaparición en 1821 de su caudillo prin-

14- La misma denominación ya había sido utilizada anteriormente por Simón Bolivar al enfrentarse contra los "llaneros" venezolanos (1813). En el caso de Chile, la "guerra a muerte" comenzó en 1818, dando lugar a una "guerra sin cuartel", en la que realistas y patriotas se enfrentaban para "vencer o morir". Autores chilenos como Vicuña Mackenna (1972), consideran que esta guerra culminó con la batalla de Ayacucho en 1824 porque para entonces, según su análisis, ya habrían desaparecido los principales ideólogos de las guerrillas realistas.

15-Vicente Benavídez (chileno) fue nombrado coronel de las fuerzas realistas del sur de Chile por el Virrey Pezuela en 1819. Fue el real inspirador de la organización de los grupos de guerrillas y ejecutor de variadas estrategias politicas para desestabilizar al incipiente gobierno independiente de Chile. Los discursos oficiales de la época crearon una imagen estereotipada del caudillo hasta convertirlo en sinónimo de barbarie y bandidismo. Detrás de esta visión tendenciosa existía una cruenta lucha por el poder. (MANARA, Carla 1998). 
cipal, Vicente Benavídez ${ }^{15}$, el accionar de las montoneras continuó en Chile hasta 1824 bajo la conducción del español Pico. A partir de 1825, el liderazgo de los hermanos Pincheira ${ }^{16}$ asentados en tierras argentinas marcó la continuidad de la resistencia realista hasta 1832.

El centro de operaciones se trasladó a las tierras indígenas del noroeste neuquino, donde los Pincheira reorganizaron las fuerzas dispersas de Chile, refugiándose en los ricos y protegidos valles de Varvarco y de las Lagunas de Epulafquen. Cabecillas de las montoneras que continuaron la guerra en forma de guerrillas, fueron incorporando a sus filas distintos actores sociales que hemos denominado "montoneros fronterizos".

Nos referimos a fuerzas heterogéneas que, organizadas bajo la bandera del rey y en pro de un objetivo común -aunque no desligadas de intereses particulares- se movilizaron como un frente de oposición armada, al nuevo orden independiente en la frontera argentino-chilena. Así españoles, criollos e indígenas, cada uno con sus particulares intereses, lograron la cohesión suficiente como para jaquear durante dos décadas al mal pertrechado ejército patriota del Sur. Estas fuerzas opositoras, expresaban fundamentalmente una profunda confrontación ideológica, cuestionando, sin dudas, la legitimidad del nuevo gobierno republicano ${ }^{17}$.

Algunos militares españoles, ideólogos e inspiradores de la resistencia armada; representantes del clero predispuestos a santificar los ataques y saqueos perpetrados sobre los poblados; pequeños campesinos e inquilinos del sur, sumidos en una profunda crisis provocadas por prolongadas hambrunas, opresión e injusticias; desertores del ejército patrio mal pagados y hambreados; distintos grupos indígenas más delincuentes comunes y oportunistas fuera de la ley, emigraron al este cordillerano poniéndose a disposición de los sucesivos jefes guerrilleros.

Sobrevivir bajo la protección de los líderes de la resistencia, llegó a ser la única opción de los pobladores del mundo rural, frente a la desestructuración del orden social producido en los primeros años de la vida independiente. De allí que familias enteras emigraran a territorio argentino ante la posibilidad de asegurarse al menos protección y comida. Las tierras neuquinas siguieron sien-

16-Nos referimos a Antonio, Santos, Pablo y José Antonio. En este orden y sucesivamente actuaron como jefes de los grupos guerrilleros durante 15 años.

17-En documentación privada de Vicente Benavídez se encuentran claras referencias al gobierno "despótico y arbitrario" del "inicuo O'Higgins", y a los "bárbaros caprichos" que provocaron la "lamentable catástrofe de Santiago", sede del gobierno patrio. En: "Carta de Benavidez al General Don José Migue] Carrera proponiéndole su alianza antes de emprender su campaña de 1820". (V. MACKENNA, 1972:837839). 
do uno de los espacios de reaseguro, propicias para brindar protección e impunidad.

\section{La movilización indígena y la convivencia en las fronteras}

La resistencia armada en nombre del monarca español, no podría haberse consolidado sin la participación activa de los grupos indígenas de la Araucanía primero, bajo la conducción de Mangin y Mariluán, y de los pehuenches cordilleranos después, principales aliados de los Pincheira. Caciques como Martín Toriano, Juan Neculmán, Chuica, Coleto, Mulato y Trecamán posibilitaron la organización de malones que atacaban simultáneamente poblados distantes a uno y otro lado de los Andes.

Los pehuenches, como lo habían sido antes los mapuches chilenos, se convirtieron en activos partícipes y colaboradores que pronto aprendieron a sacar provecho del reparto del botín, que les posibilitaba entre otras cosas, la obtención de las codiciadas mujeres blancas.

Sin duda, los caciques amigos, con la instalación de la república, tenían mucho más que perder que lo que podían ganar. Durante la colonia se los había reconocido como autoridades legítimas sobre sus gentes y territorios, se los trataba con deferencia, se los agasajaba en los parlamentos y puestos fronterizos y hasta se les asignaba un sueldo equivalente al de soldados. El nuevo orden político pretendía restarles sus privilegios y transformarlos en simples ciudadanos.

Conocida la nueva situación y el nuevo escenario nos preguntamos: ¿de qué manera se relacionaron los indígenas neuquinos con los Pincheira?; icómo afectó esta alianza a la organización interna de las tribus y al modelo económico que veníamos analizando? y iqué ventajas obtenía cada uno de ellos?

Resulta interesante analizar la actitud de los pehuenches en el marco de las guerras de independencia. Para fines del XVIII, tanto Ambrosio O'Higgins desde Chile como Francisco de Amigorena desde Mendoza ${ }^{18}$, después de una esmerada política de atracción y ayuda militar, habían logrado que sus aliados indios se convirtieran en leales vasallos del rey en pro de una política de pacificación. Ese respeto y fidelidad hacia el lejano soberano, fue incentivado por los Pincheira, quienes acentuaron en ellos esa convicción, fomentando la animadversión hacia los patriotas.

18-Ambrosio O'Higgins (1788-1796) fue nombrado Gobernador y Capitán General de Chile mientras se desempeñaba como Intendente de Concepción. Francisco de Amigorena fue Gobernador y Comandante de Fronteras de Cuyo. 
Los estratégicos y casi inaccesibles reductos del noroeste pertenecían a los pehuenches, quienes durante la colonia, nunca habían aceptado que araucanos o españoles se asentaran en forma permanente en sus tierras ${ }^{19}$. En un principio se limitaron a permitir el paso de los realistas, tal vez más por agrado y conveniencia que por la fuerza, pero después les dieron hospitalidad y pusieron a su disposición los ricos valles que ellos dominaban.

Los montoneros se asentaron cerca de las tolderías indígenas llegando a conformar aldeas estables, donde los jefes principales levantaron casas de paja muy grandes y cómodas, rodeadas de numerosas casuchas de cuero fácilmente transportables de sus secuaces que, por relaciones de familia y de amistad o en la condición de cautivos, integraban la población que seguía a los montoneros $^{20}$. Las familias estaban organizadas y la división del trabajo permitía el mantenimiento de la población concentrada. Lamentablemente las fuentes de la época brindan poca información al respecto.

La actividad ganadera predominante en la etapa colonial continúa, acrecentándose con lo obtenido en los malones, manteniendo los circuitos mercantiles anteriores. Los partes militares dan cuenta de la abundancia de ganados que poseían, producto de los saqueos a las haciendas vecinas ${ }^{21}$.

Es lógico suponer también, que la agricultura, poco practicada por los indígenas pehuenches del norte en el siglo anterior, debió desarrollarse favorablemente a causa de la instalación de numerosas familias campesinas en una zona de buenas tierras. A partir de aquí, y ante los pocos datos aportados por las crónicas, formularemos una serie de interrogantes que, una vez resueltos, podrían ir conformando un marco apropiado para comprender la realidad histórica.

Llama la atención cómo los indígenas que en la etapa anterior se habían mostrado renuentes a la integración con los blancos, ofrecían ahora sus tierras $y$ reductos innaccesibles del noroeste neuquino y sur mendocino. Comprender cuál fue el grado de interacción en esta convivencia de blancos e indios resulta de fundamental importancia. Si bien habían mantenido una buena relación en la frontera, los grupos nativos habían rechazado siempre la integración y la

19-En el siglo XVIII cuando los pehuenches estuvieron en guerra con los huilliches recibieron ayuda militar del ejército de Mendoza y de Chile. La presencia de soldados fue esporádica y según las demandas de los indígenas pero nunca revistieron las características de asentamientos estables que encontramos en el siglo XIX.

20-Al respecto, las "Memorias del Coronel Don Jorge Beauchef" constituyen un valioso aporte. (VICUÑA MACKENNA, B. 1972).

21-Partes militares del Gral. M. Bulnes durante su expedición contra los Pincheira en 1832. (BARROS ARANA, D. 1902). 
idea de residir cerca de los blancos. Quizás, la posibilidad de una ocupación real de la Araucanía y la presencia efectiva del ejército patriota sobre los principales pasos cordilleranos estaba poniendo en peligro la seguridad que siempre habían tenido. Incluso algunos centros poblados como Chillán, donde acostumbraban hacer sus intercambios, se habían tornado muy peligrosos para los pehuenches.

El contar en sus propias tierras con una fuerza, que poseía armas de fuego y practicaba un estricto adiestramiento a cargo de jefes con tradición militar ${ }^{22}$, debió ser un factor determinante que les aseguraba protección ante la posibilidad de cualquier ataque externo. Además, la posibilidad de juntar una importante cantidad de hombres para organizar los malones y asaltos, aumentó la frecuencia de los mismos e incrementó considerablemente el volúmen de lo obtenido.

La inestabilidad en la frontera a causa de la guerra a muerte y la presencia efectiva del ejército patrio, les dificultaba la colocación de sus productos en Chile. Claro está, que la resistencia contó con la alianza inapreciable de varios hacendados del sur chileno, todavía muchos de ellos partidarios del rey, quienes por su posición social y económica estaban en condiciones de realizar un doble juego hasta tanto se definiera el rumbo político que les permitiera mantener sus beneficios económicos.

La colaboración con las fuerzas pincheirinas les aseguraba el acceso a los ganados que se maloneaban en Cuyo y en las pampas. Fueron además los aliados necesarios para concretar transacciones comerciales, que los montoneros por su clandestinidad no podían realizar, sin correr el riesgo de ser capturados al salir de sus refugios. De tal modo, creemos que los circuitos mercantiles, mantuvieron su funcionamiento tradicional, ampliaron significativamente el radio de acción y aumentaron la cantidad de animales maloneados. En cuanto al destino de estos importantes arreos, todos los datos nos indican que el mayor porcentaje, servía para el abastecimiento de las cientos de familias emigradas instaladas en sus refugios y el excedente se lo comercializaba en los mercados de Chile, especialmente a través de los hacendados amigos y protectores. 


\section{El modus vivendi de los montoneros}

Para mantener movilizados a los grupos de guerrillas en el sur de Chile, el mismo virrey enviaba desde Perú convoyes con variados elementos demandados por las fuerzas de resistencia. Auxilios que perduraron hasta la derrota de Ayacucho en 1824, año en el que se expulsó a los realistas de Lima. Detrás de estos envíos materiales, el incondicional apoyo ideológico del único representante de la corona española en América, legitimaba el accionar montonero.

A partir de 1825, en plena etapa pincheirina, llegaban a los refugios montoneros víveres enviados por mujeres "colaboracionistas" que no eran otras que las madres y esposas de los hombres de la resistencia. Por otro lado, recibían mercancías y dinero que aportaban a la causa comerciantes de Chillán o Mendoza. También contaban con el apoyo de gente pudiente de las ciudades realistas como Parral y de algunos políticos que actuaban como informantes $y$ como intermediarios en transacciones comerciales ${ }^{23}$.

Las características de una geografía inaccesible permitió la construcción de una red de centros de operaciones conectados eficazmente entre $s^{24}$. Los grupos pincheirinos estaban asentados no sólo en Neuquén sino también en Mendoza y la Pampa y esto les garantizaba un reaseguro y una rápida huída ${ }^{25}$. Ante esto, el ejército del sur fracasó en reiteradas oportunidades porque al llegar a las tierras pehuenches las encontraban vacías de hombres y haciendas, dado que éstos, avisados por sus espías ya se habían trasladado a otro de sus reductos. La organización militar de los realistas, sumado al dominio que los indígenas tenían del terreno, rutas y pasos les otorgó ventajas sobre el enemigo.

El hecho de que en Neuquén no existiera ningún asentamiento blanco o fortín, convertía a los nativos y sus alidos en seres libres de toda dominación.

23-Como ejemplo podemos citar el caso del Juez Diputado Lascano, del Distrito de Chillán, quien estaba en permanente contacto con los pincheirinos. (CONTADOR VALENZUELA; A.M. 1989).

24-Las formas de comunicación entre los grupos eran variadas. En primer lugar cabe destacar el rol de los espias e informantes, amplios conocedores de los caminos, que recorrían largas distancias llevando mensajes o noticias. En segundo lugar, existían códigos entre los grupos tales como la "señal del hacha", que consistía en asestar determinados golpes en los árboles que se transmitían en forma de eco; señales de humo y la utilización de un instrumento de sonido muy particular.

25-Los "montoneros fronterizos" tuvieron varios asentamientos intercomunicados tales como Roble Huacho en la cordillera occidental, Girones entre el Atuel y el Salado y el refugio de Chicalco en la Pampa. Los refugios en Neuquén localizados en las lagunas de Epulafquen y Varvarco, fueron los más seguros y estables. 
La seguridad de estos reductos es mencionada reiteradamente en las fuentes ${ }^{26}$. Desde este espacio fronterizo, las fuerzas de los Pincheira se involucraron y participaron decididamente en las guerras civiles desatadas durante las primeras décadas independentistas, adhiriendo a uno u otro bando. Era común que estos firmaran acuerdos de igual a igual con las facciones en pugna y que simultáneamente fomentaran conspiraciones interétnicas que oscurecían el panorama ${ }^{27}$.

Esta conjunción de factores debieron ser la causa de una resistencia exitosa y prolongada al este de la cordillera. Recién en 1832 el general chileno Bulnes pudo derrotar al último Pincheira.

El panorama descripto se complejiza cuando analizamos la entrada masiva de tribus araucanas a territorio argentino, que había comenzado a partir de 1820. La intranquilidad generada por las luchas independentistas en el sur de Chile, determinó que numerosos grupos, especialmente de la región de Boroa, decidieran emigrar al este de la cordillera. Por un lado buscaban la paz y seguridad que les aseguraba el traspaso de los Andes, y por otro, la posibilidad de controlar los sitios de obtención de animales y provisión de sal, eliminando así los intermediarios.

Aparentemente los territorios pehuenches fueron respetados y el control de los pasos cordilleranos continuaron en manos de los principales caciques locales. La penetración mapuche fue ganando espacio hacia el noreste de Neuquén impactando sobre los tehuelches septentrionales de Río Negro y sobre los grupos pampas que perdieron su supremacía en lugares económicamente estratégicos como Sierra de la Ventana y Salinas Grandes.

Durante los años de la guerra a muerte, los tradicionales conflictos inter-

26-Los Partes Militares de las campañas contra los pincheirinos como las del Brigadier José Manuel Borgoño (1826) y la del Gral. Manuel Bulnes (1832) coinciden en destacar que las expediciones en los valles neuquinos eran empresas fatigosas, en las que los indígenas solían sacar ventajas por su dominio de la difícil geografia y la disponibilidad de mejores caballos. Cabe señalar que el acceso a las tierras pehuenches fue posible en gran parte por la información proporcionada por ex-pincheirinos a cambio del indulto. Aún años más tarde cuando los ranqueles vieron diezmadas sus filas, a partir de los ataques ordenados por Rosas, se retiraron hacia Neuquén para dejar sus familias a buen recaudo y solicitar desde allí refuerzos a los caciques chilenos. Véase (RATTO, S.1996).

27-En 1829 se firmó el tratado del Carrizal entre las autoridades de Mendoza y José Antonio Pinchiera para terminar con los asaltos e invasiones realistas a la desguarnecida frontera mendocina. Se acordó nombrar al coronel Pincheira Comandante General de la Frontera Sur y se estableció, entre otros asuntos, el comercio libre entre las partes. Con este tratado, el caudillo guerrillero se convirtió en el jefe militar más importante de la frontera sur, siendo que hasta entonces había sido el principal responsable de las montoneras que asolaban la misma. Este hecho permite conjeturar acerca de las estrategias y las debilidades del gobierno patrio. 
tribales se agudizaron y definieron una red de alianzas tanto con el bando realista como con el patriota. Al trasladarse al territorio argentino, las antiguas rivalidades y la definición en pro o en contra de monarquistas o republicanos, los llevó indefectiblemente a involucrarse en las guerras de la independencia.

Cabe preguntarnos cuál fue la incidencia de la fuerte presencia mapuche sobre el funcionamiento del modelo económico planteado. Puede pensarse al respecto, que los acuerdos y relaciones de parentesco de los indígenas de Neuquén con las etnias provenientes de Chile, fueron muy convenientes para asegurar la adecuada obtención y circulación de los bienes demandados. La ocupación de los enclaves estratégicos por los contingentes trasandinos no habría modificado en demasía el funcionamiento de la actividad ganadera. Es muy probable que la alianza entre los Pincheira, mapuches y pehuenches, haya contribuido a consolidar y a ampliar los circuitos mercantiles preexistentes y acrecentar el volumen de sus ganados. Profundizar acerca de esta cuestión nos permitirá conocer un poco más de lo acontecido en la frontera surandina en los inicios de la etapa republicana.

\section{La perdurabilidad de la violencia y los nuevos malones}

La campaña del Ejército chileno al mando del Gral. Bulnes en 1832 terminó con el último de los Pincheira, pero los resabios de la violencia de la guerra a muerte se prolongaron por algunos años más a causa de la presencia del cacique patriota Venancio Coñuepán en las pampas ${ }^{28}$. Este cacique junto con el alférez Juan de Dios Montero y varios cientos de soldados habían sido enviados en 1827 por el gobierno chileno para perseguir a los indígenas pincheirinos y convencer a los caciques aliados de adherirse a los patriotas. Cuando fue vencida finalmente la organización montonera, Coñuepán continuó persiguiendo a los antiguos pro-realistas y los enfrentamientos se mantuvieron durante algunos años más. Fuertes resabios de las luchas de antaño seguían movilizando a los bandos en busca de venganza ${ }^{29}$.

Las pampas se convirtieron en un escenario donde continuaron recreándose profundos conflictos y rivaliadades. Este contingente de patriotas chilenos tuvo dificultad para regresar a su tierra. Rosas en una carta enviada a Quiroga en 1833, confirmaba que la mayor dificultad para la retirada de estos era a causa de "los enemigos que tiene en el camino" (Villar, D. y Jiménez, J. F,1996). Es

28-(VARELA-FONT-CUNEO y MANARA 1998:Cap.VII).

29-Venancio Coñuepán, aparentemente, fue asesinado en un confuso episodio en Bahía Blanca en 1836.

- Instituto de Historia Regional - Facultad de Ciencias Humanas - Universidad Nacional de La Pampa - 
probable, que los pehuenches, dueños de los pasos cordilleranos e integrantes y firmes aliados de las fuerzas pincheirinas, hayan sido también un obstáculo para el regreso de los chilenos. Como antecedente de dicha enemistad recordemos el conflicto desatado en 1824, cuando el alférez Montero, yerno de Coñuepán, se apoderó de las salinas de Truquico, pertenecientes a los pehuenches neuquinos, privándolos de este importante recurso. En tales circunstancias, los indígenas cordilleranos se convirtieron en peligrosos enemigos de los recién llegados, quienes debieron pedir protección y auxilio al fuerte Independencia (Tandil).

Asimismo, los robos a las haciendas continuaron por muchos años más. Ya no era el caudillo y montonero realista, José Antonio Pincheira el que incentivaba los malones, sino que, nuevos personajes trasandinos aparecen capitaneando los asaltos a los campos argentinos con total impunidad. Entre éstos se destacaban capitanes de amigos con sus soldados y administradores de importantes hacendados chilenos en combinación con las tribus araucanas ${ }^{30}$. Incluso algunos ex-oficiales pincheirinos, como José Antono Zúñiga y Domingo Salvo, nombrados capitanes del ejército chileno, estimularon y organizaron a grupos indígenas para que malonearan en Argentina. El fruto de estos saqueos era luego comercializado por aquellos en los mercados chilenos. Así lo confirmaba el cacique Cristiano en oportunidad de ser interrogado por las autoridades mendocinas:

"...que los indios conocidos con el nombre de Mulucches siendo estos varias tribus amigas del Gobno (sic) de Chile y bajo el mando del Sargento Mayor Comisario Zúñiga todos los años pasan las cordilleras con previo consentimiento de Zúniga y vienen á robar ganados á la Rep. Argentina con lo que se vuelven á la de Chile, y alli son vendidas por lo general en las fronteras de Concepción y otros varios puntos del Sud, no ignorando los compradores que esta hacienda es robada en las provincias argentinas; otros especulan nternándose a donde están los mismos indios y alli celebran sus contratos..." ${ }^{31}$

Una vez derrotado el último de los Pincheira, desde el frente bonaerense, Rosas advirtió que era el momento propicio para llevar a cabo su bien planifi-

30-Tal es el caso de Lujardo Jara, capitán de amigos de las tribus araucanas que en connivencia con su compatriota Pedro Herrera, administrador del rico hacendado don Francisco Méndez Urrejola, utilizaban la antigua rastrillada pincheirina, conocida tradicionalmente como el "camino de los chilenos", para malonear grandes arreos de ganado en las pampas. Cfr. (MAZA, J.I. 1990).

31-Cfr. Gobiernos y agentes diplomáticos de la República Argentina. Chile, 1836-1847. Dicho cuerpo documental consta de folios varios, cartas y comunicaciones, p. 473. 
cada "campaña al desierto" de 1833. Terminada ésta, se logró una relativa tranquilidad en la frontera. Pero al poco tiempo, y a raíz de la imposibilidad de mantener los fuertes establecidos en las tierras conquistadas, lentamente los contingentes indígenas que se habían refugiado al oeste de la cordillera, retornaron. Muchos de ellos movilizados por hábiles personajes que desde el otro lado de los Andes seguían demandando el ganado pampeano.

Los efectos de la campaña militar, recayeron fundamentalmente sobre los grupos de las pampas, no así sobre las tribus del sector cordillerano. El modelo económico de éstos no se modificó estructuralmente $y$, rápidamente, retomaron sus estrategias de maloneo. La presencia efectiva de los fortines en la provincia de Buenos Aires, desvió momentáneamente sus correrías hacia las estancias de Mendoza, San Luis, Córdoba y Santa Fe.

Para entonces la demanda de animales por parte de los hacendados chilenos se incrementó, estimulando la organización de grandes malones en búsqueda del ganado necesario para mantener el comercio trasandino.

El malón adquirió rasgos diferentes. Se convirtió en una real empresa económica, cuya organización requería de amplios conocimientos geográficos, de una minuciosa planificación y de la participación de cientos de lanceros pertenecientes a tribus de ambos lados de la cordillera. De acuerdo a la cantidad de hombres y caballos que se aportaba a la empresa, cada cacique obtenía un porcentaje del botín. Se recrudeció la tradicional práctica maloquera provocando a los hacendados cuantiosas pérdidas e innumerables conflictos fronterizos. La complejidad organizativa respondía evidentemente a la gran cantidad de ganado obtenido, que oscilaría sin exagerar entre 20.000 y 40.000 cabezas anuales ${ }^{32}$.

\section{Los grandes cacicatos}

Para la segunda mitad del siglo XIX, encontramos tres grandes cacicatos en territorio neuquino. El cacique Purrán al norte, Reuquecura en el centro y Sayhueque al sur. Estos grandes jefes seguían comercializando miles de

32-Algunos años antes de la expedición militar de 1879, Olascoaga había informado al gobierno argentino que el volumen de animales robados era muy elevado y que los pehuenches eran los mayores responsables de su traslado a Chile:"..la exportación de ganado para Chile, se calcula la cifra de ganado robado de nuestras provincias en 40.000 cabezas al año, cuya mayor parte la venden los Pehuenches que viven en perfecta armonía con la República chilena, recibiendo en cambio, en especies, un valor de 2 o 3 pesos fuertes por cabeza..." Por lo tanto, según afirmaba Olascoaga, al cortarse el comercio con Chile se anularía el mayor incentivo de los indios para robar ganado.Cfr. (OLASCOAGA, M. 1974:72). 
cabezas de ganado en las ferias chilenas, productos en gran parte de jugosos malones. Es cierto que esta actividad tan lucrativa hasta entonces, en la década previa a la campaña militar, estaba siendo frenada por las autoridades argentinas mediante reiterados pactos.

El análisis en particular de cada uno de estos caciques mostrará distintas actitudes frente a las estrategias de los gobiernos tanto argentinos como chilenos.

\section{Feliciano Purrán}

El cacique Purrán, había firmado en 1870, un tratado de amistad con Don Basilio Urrutia, jefe de operaciones de la Araucanía, comprometíendose a auxiliar al gobierno de Chile en caso de cualquier ataque de las tribus moluches y a proteger a las personas y haciendas de los chilenos que arrendaban sus tierras a los caciques pehuenches. A cambio, recibiría ciento veinte pesos anuales y la posibilidad del nombramiento de un comisionado, que velaría por sus intereses comerciales en la plaza de Antuco (Hux 1991:50-51).

Tres años después firmó un nuevo tratado, esta vez con las autoridades del fuerte de San Rafael en Mendoza. Por el mismo, el gobierno nacional trató de neutralizar el tratado de 1870, procurando que los caciques del norte neuquino reconocieran la soberanía argentina en esos territorios, comprometiéndose a su vez, respetar el sur de río Neuquén como residencia de las tribus; costear la educación primaria para los hijos de caciques y capitanejos; permitir el libre comercio entre las tribus y las poblaciones argentinas; pagar un sueldo de 200 pesos al cacique Purrán; entregar cada seis meses, azúcar, yerba, tabaco, papel y jabón, a lo que se agregaba para los mocetones aguardiente y vino, más trescientas yeguas anuales. En calidad de regalo, se entregaba a los cacique principales, un vestuario completo y cada dos años una montura de buena calidad.

La aceptación de los tratados de paz con ambos países, muestra una gran habilidad diplomática del gran jefe pehuenche, logrando con estos acuerdos, un intercambio de bienes y favores. Estas relaciones eran muy frágiles en un sentido, pero muy necesarias por otro, implicando un juego ambiguo de las partes.

Si bien estas alianzas de paz fueron concebidas por el gobierno argentino con el objetivo de aplacar la actividad malonera por parte de Purrán, quien según las fuentes, "en los últimos años no salía a dar malón" (Pechmann, 1980), la demanda creciente de ganados ejercida por ricos hacendados y comerciantes chilenos, seguía siendo el principal estímulo para los saqueos sobre las haciendas argentinas. 
Así, algunos caciques integrantes de la liga del gran cacique picunche, continuaban dando malón. Por ejemplo, Udalman, cacique pehuenche de Chile, posiblemente traído por estancieros chilenos para cuidar sus veranadas en tierras neuquinas, en 1873 invadió la frontera mendocina, repitiendo su accionar al año siguiente (HUX, 1991).

Purrán, dominaba un extenso y estratégico territorio de características muy peculiares dado que era el paso obligado hacia las principales ciudades chilenas del sur, o hacia el Colorado (Alvarez, G. 1985). Tenía varios asentamientos estables con campos de veranada e invernada de buenas tierras y excelentes recursos. De él dependían numerosos caciques y capitanejos ${ }^{33}$.

No resulta fácil analizar el rol de este cacique fronterizo a causa de la compleja red de relaciones de la que era partícipe. Por un lado mantenía buenas relaciones diplomáticas con el gobierno chileno que protegía sus transacciones en las plazas trasandinas; al mismo tiempo hacía alianzas con personajes ambivalentes como el mencionado Zúniga, conocido traficante de haciendas (Hux 1992:186) y estaba asociado a los intereses de los hacendados arrendatarios $^{34}$. Por otro, intentaba mantener buenas relaciones con las autoridades argentinas, mientras no lesionaran sus intereses particulares.

\section{Reuquecura}

El cacique Reuquecura que dominaba la franja central de Neuquén, era considerado como un "intruso" por parte de los indígenas argentinos, dado su origen chileno (Alvarez, 1985). Intervino en numerosos malones junto a las fuerzas de su hermano Calfucurá, demostrando en cada oportunidad su poder de convocatoria. En 1869 le envió al gran cacique un gran contingente de hombres para atacar Cármen de Patagones; en 1870 formó parte de uno de los malones más grandes dirigido por Calfucurá contra Tres Arroyos, arreando cerca de 40.000 animales y en 1872 también participó del combate de San Carlos en la frontera oeste de Buenos Aires, malón en el que intervinieron unos 6.000 indios y que fuera la última gran acción del gran jefe de la dinastía Curá (Walther, 1964:152-156).

33- Según G. Alvarez (1985) dependían de Purrán 14 caciques secundarios y 17 capitanejos. Mientras que los partes militares de la IV División de la campaña militar de 1879 , señalan que tenía en total 22 cacique subordinados. Entre todos podia sumar entre mil y dos mil lanzas, particularmente en ocasión de dar un malón.

34-Podemos particularizar la presencia de dos poderosos hacendados: Méndez Urrejola y Price (o Pray). El primero era procedente de Concepción y tenía su establecimiento denominado "Látigo verde" a $5 \mathrm{~km}$. de la confluencia del río Varvarco con el Neuquén. En el otro caso, se trata de un hacendado de origen inglés, instalado en el valle de las lagunas de Epulafquen donde aparentemente había más hacendados. 
Reuquecura desde sus tierras de Neuquén, controlaba la comercialización de los ganados que le eran remitidos desde las pampas e ingresaban a los mercados chilenos $^{35}$. No respondía a las órdenes de Sayhueque ni a las de Purrán, y actuaba como una cuña entre los territorios dominados por éstos. Era un permanente reaseguro de las huestes araucanas que tenían el tránsito garantizado por tierras neuquinas.

\section{Valentín Sahyhueque}

En el caso del "Emperador de las Manzanas", Valentín Sayhueque, para 1870 , aparece claramente aliado al gobierno argentino, al punto de negarse a participar en la invasión que Calfucurá planeaba sobre la población de Carmen de Patagones, con la que aquél comerciaba (Schoo Lastra, 1977).

Las fuentes dan cuenta de cierta actividad malonera durante las décadas anteriores, actividad que aparentemente abandonó cuando el gobierno argentino comenzó a entregarle cuantiosas cabezas de ganado y raciones varias. Según observó Musters:

"...al cacique no le convenía intervenir len los malones sobre Carmen de Patagones] porque perdería inevitablemnete las valiosas provisiones de caballos y de vacas que le daba el gobierno bonaerense y que era más provechoso recibir las raciones anuales que saquear y desbaratar las colonias del río Negro" (Musters, 1964:318).

Aunque Sahyhueque no participara de los malones, caciques de tribus disgregadas seguían dedicándose al pillaje (Schoo Lastra, 1977:145).

Este cacique era muy rico, poderoso y respetado. Ejercía dominio sobre un vasto y codiciado territorio ${ }^{36}$. Sus tolderías llamaron la atención del inglés Musters, quien destacó particurlamente la riqueza y el grado de "civilización" que denotaban sus aposentos (Musters, 1964:314).

Sahyhueque dominaba los pasos cordilleranos del sur neuquino y mantenía un control efectivo sobre el tráfico de animales que por ellos se realizaba. Al respecto, Musters señala la importancia de contar con el aval del cacique para transitar por este territorio. Para ello, puede inferirse que era necesario pagar una especie de peaje, probablemente en animales, de lo que habría surgido parte de la riqueza del cacique. El caso de los valdivianos a los que hace referencia Musters corrrobora lo antes dicho: 
"En uno de los valles ...dimos de pronto con los valdivianos que volvían a su país arreando el ganado por el camino; Cheoeque (Sahyhueque) habia enviado a los picunches, que ocupaban las tierras inmediatas a los únicos pasos conocidos a través de la cordillera, para que los dejaran pasar sin molestarlos; a pesar de esa precaución, los valdivianos nada seguros estaban de que los picunches no los aliviaran del trabajo de arrear sus animales cuando llegasen a las cercanías de los pasos... los valdivianos habian estado detenidos más de un año espérando un salvoconducto..." (Musters, 1964:317)

Todos estos datos indican que los antiguos circuitos mercantiles seguían vigentes. Villarino ya había dado cuenta de la articulación de rutas y pasos por los cuales se arreaban grandes cantidades de animales provenientes de las pampas con destino final a Valdivia.

A diferencia de Purrán, Sahyhueque permaneció fiel a sus acuerdos con el gobierno argentino ${ }^{37}$. Había apostado a una de las partes, y convencido de que iba a ser de igual modo respetado, rechazó toda propueta de afectar los intereses nacionales. Cuando advirtió que las fuerzas militares en la campaña de 1880 se acercaban a sus dominios para someterlo, traicionando los pactos anteriores, huyó al sur de la patagonia hasta su rendición final en 1885.

Vemos así, que los sucesivos acuerdos entre las autoridades argentinas y los distintos grupos indígenas, fueron fundamentales para contener momentáneamente los ataques en las fronteras. Pero en definitiva, los gobiernos estaban poniendo en juego hábiles estrategias de dilación y persuasión. El plan político implementado, permitió ir prorrogando la decisión, por entonces irrevocable, de ocupar las tierras patagónicas.

La campaña militar de 1879 provocó el quiebre definitivo del mundo indígena. Neuquén dejó de ser el tradicional reaseguro fronterizo para los grupos nativos, mestizos y criollos. Este espacio siempre caracterizado por una singular convivencia de diferencias amparadas en la impunidad, fue invadido por el avance militar. La presencia efectiva de las fuerzas regulares fue la única instancia que logró romper su estratégico y bien resguradado aislamiento.

37-Así lo corroboran los conceptos de Julio A. Roca en un informe presentado en el Congreso Nacional en 1879: "El único cacique que he creido merezca ser considerado por su conducta siempre fiel y la buena comportación de su tribu que no ha figurado en malones, es Sahyhueque el de las manzanas...".(CURRUHINCA- ROUX 1986:156). 


\section{A modo de síntesis}

Evidentemente, la compleja red de relaciones económicas y sociales entabladas a lo largo de la colonia, no pudo ser interrumpida con el advenimiento de la etapa republicana.

El modelo económico perduró, asimilando cambios coyunturales a lo largo de dos siglos muy complejos, sin modificar básicamente su esencia. Pudo sortear satisfactoriamente los efectos de la campaña de 1833 y continuar desarrollándose con eficacia hasta fines del siglo XIX. Solamente la contundencia de las campañas militares de $1879-1885$, pudieron desestabilizar las relaciones construidas por blancos e indios en etapas anteriores.

Los grandes cacicatos neuquinos fueron desbaratados y sus dominios pasaron a poder del Estado. Los tradicionales circuitos mercantiles hacia Chile, por siglos en manos de los indígenas, fueron definitivamente desarticulados. Sin embargo, la instalación de los fortines, la imposición de límites políticos y el afianzamiento de la soberanía nacional, no impidió que la cordillera permaneciera siendo un ámbito de interrelación de viejos patrones culturales y económicos. Claro está, que ahora serían los "huincas" quienes retomarían el control de las relaciones fronterizas y las antiguas prácticas del intercambio.

\section{Referencias Bibliograficas}

*ALVAREZ, Gregorio (1985). Neuquén. Historia, geografía y toponimia. Neuquén, T. 4.

*ASSADOURIAN, Carlos Sempat (1982). El sistema de la economía colonial. Lima, IEP.

*BAIED, Carlos (1985). Trashumance and agrarian geography in north- estern, Neuquén, Argentine. Patagonia. American Antrophologycal Association Abstract 84 ph., Annual Meeting, Washington, D.C.

*BARROS ARANA, Diego (1902). Historia General de Chile. Santiago, T. XVI. *BENGOA, José (1992). Conquista y barbarie. Chile, Ed. Sudamericana.

*CONTADOR VALENZUELA,Ana M.(1989). Bandidaje y guerrilla. Tesis de la Maestría de Historia Andina. Santiago de Chile. Mimeo.

*COX, Guillermo (1863). Viaje a las rejiones septentrionales de la Patagonia. Santiago de Chile, Imprenta Nacional.

*CURRUHINCA-ROUX (1986). Sahyhueque. El último cacique. Bs. As., Plus Ultra.

*DE ANGELIS, Pedro (1969). Colección de obras y documentos. Bs. As., Plus Ultra.

*GOÑI, R.(1986). "Arqueología de sitios tardíos en el valle del río Malleo. Prov. de Neuquén". En: Relaciones de la sociedad Argentina de Antropología. Bs. As., T.XVII, $\mathrm{N}^{\circ} 1$.

${ }^{*}$ HUX, Meinrado (1991). Caciques pehuneches. Bs.As., Marymar. 
*HUX, M. (1992). Cacique borogas y araucanos. Buenos Aires, Marymar.

*MANARA, Carla (1998)."Un genio del mal. La visión oficial de un caudillo contrarrevolucionario". Ponencia presentada en: Cuartas Jornadas de Historia regional. Universidad Nacional de la Patagonia Austral, Caleta Olivia.

*MANDRINI, Raúl (1984)."La base económica de los cacicatos araucanos del actual territorio argentino". En: Sextas Jornadas de Historia Económica. Córdoba, Vaquería.

*MAZA, Juan Isidro (1990). Revista de Estudios Regionales. Mendoza, CEIDER, Universidad Nacional de Cuyo, $\mathrm{N}^{\circ} 6$.

*MENDEZ BELTRAN, Luz María (1982)."La organización de los parlamentos indios en el siglo XVIII". En: Villalobos, S. y otros: Relaciones fronterizas en la Araucanía. Santiago, Ed. Univ.Católica de Chile.

*MUSTERS, George (1964). Vida entre los patagones. Bs.As., Solar-Hachette. *OLASCOAGA, Manuel (1974). Estudio topográfico de la Pampa y Rio Negro. Bs. As., Eudeba.

*PECHMANN, Guillermo (1980). El campamento de 1878. Algunos cuentos históricos de fronteras y campañas. Bs. As., Eudeba. ( $1^{\circ}$ ed. 1938).

*KEUN, Ricardo 1986 Así nació la frontera... Santiago de Chile, Ed. Antártica *POEPPIG, E.(1960). Un testigo en la alborada de Chile. 1826-1829. Santiago, Zig-Zag.

*RATTO, Silvia (1996). "Conflictos y armonías en la frontera bonaerense. 18341840". En: Entrepasados. Revista de Histora, No 11.

*SCHOO LASTRA, Dionisio (1977). El indio del desierto. 1535-1879. Buenos Aires, Ed. Goncourt.

*TANDETER, Enrique (1992). Coacción y mercado. La minería de la plata en el Potosí colonial (1692-1826). Perú, Centro de Estudios Regionales Andinos "Bartolomé de Las Casas".

*VARELA, Gladys y BISSET, Ana María (1992)."Los pehuenches en el mercado colonial". En: Revista de Historia. Neuquén, Fac. de Humanidades, UNco, $\mathrm{N}^{\circ} 3$, *VARELA, G. y BISSET, A.M.(1993). "Entre guerras, alianzas, arreos y caravanas: los indios de Neuquén en la etapa colonial". En: Bandieri, S. y otros, Historia de Neuquén. Bs As, Plus Ultra, cap. 2.

*VARELA, G. y MANARA, C.(1997)."Montoneros fronterizos: pehuenches, españoles y chilenos". En: Ponencia presentada en: VI Jornadas InterescuelasDepartamentos de Historia. Univ. Nac. de La Pampa.

*VARELA, G. y MANARA, C.(1998)."Vencer, morir o subsistir en los años de las guerras de independencia". Ponencia presentada en: Cuartas Jornadas de Historia regional. Univ. Nac. de la Patagonia Austral, Caleta Olivia.

*VARELA, G. FONT, M., CUNEO, E, y MANARA, C. (1998). Los hijos de la tierra. Dirección de Cultura, Municipalidad de San Martín de los Andes.

*VICUÑA MACKENNA, Benjamín (1972). La guerra a muerte. Santiago, Ed. Francisco Aguirre. $\left(1^{\circ}\right.$ ed 1868$)$

*VILLAR, Daniel. y JIMENEZ, Juan F. (1996)."Indios amigos". En: Pinto Rodriguez, J. (ed.): Araucanía y Pampas. Temuco, Ed.Universidad de la Frontera. *WALTHER, Juan C. (1964). La conquista del Desierto. Bs. As., Círculo Militar. 